\title{
ЭВОЛЮЦИЯ КОНЦЕПТУАЛЬНОЙ МОДЕЛИ НИЗКОПРОНИЦАЕМОГО ТРЕЩИНОВАТОГО КОЛЛЕКТОРА
}

\author{
Ахмерова Алина Валерьевна ${ }^{1}$, \\ Akhmerova.AV@gazpromneft-ntc.ru
}

Галлямова Диля Чулпановна ${ }^{1}$, Gallyamova.DCh@gazpromneft-ntc.ru

Мельников Александр Викторович1, Melnikov.AVik@gazpromneft-ntc.ru

\author{
Харитонцева Полина Анатольевна², \\ Kharitontsevapa@hw.tpu.ru \\ 1 Научно-Технический Центр «Газпром нефть», \\ Россия, 190000, г. Санкт-Петербург, наб. реки Мойки, 75-79, литер Д \\ 2 Национальный исследовательский Томский политехнический университет, \\ Россия, 634050, г. Томск, пр. Ленина, 30.
}

Актуальность исследования обусловлена необходимостью изучения сложных неоднородных трещиноватых карбонатных коллекторов, которые являются одним из источников добычи углеводородов в условиях истощающихся ресурсов терригенных коллекторов.

Цель работы - пересмотр концептуальной модели месторождения, поскольку текущая модель не в полной мере описьвает фактическое поведение пласта, затрудняет подбор технологических решений для оптимизации разработки месторождения, а также не позволяет дать оценку потенциальной эфффективности принятых решений.

Объекты: залежь пласта М1 газоконденсатно-нефтяная, массивного типа, с газовой шапкой, приуроченная к выступу карбонатного ффундамента девонского возраста на Арчинском месторождении.

Методы: интегрированный подход к анализу результатов проведенных исследований, аналитические и численные расчеты, систематизация, обобщение, структуризация исходной информации по месторождению, моделирование нескольких концепций, сопоставление с фактическими данными.

Результаты. Авторы представили альтернативный сценарий геологического строения и основных механизмов добычи рассматриваемой залежи, так как текущая модель не описывала фрактическое поведение пласта, а результаты специальных исследований свидетельствуют о сложном геологическом строении комплекса, что затрудняло детальный прогноз распространения фильтрационно-емкостных свойств коллектора. Кроме того, разрешающая частота сейсмических методов ограничивает применение полного спектра современных технологий для прогноза продуктивности, латерального распространения трещиноватости и петрофизических характеристик коллектора. Обновленная концептуальная модель предполагает, что коллектор продуктивного пласта Арчинского месторождения представлен породами двух типов: известняками и бокситоподобными породами, по данным описания керна и геофизических исследований. Трещиноватость известняков, обусловленная тектоническим фактором, характеризуется равномерным распределением по разрезу и площади месторождения, и является наиболее влияющим параметром на технологические показатели разработки. Технологический режим эксплуатации некоторых скважин и высокие депрессии приводят к конусообразованию посредствам системы трещин, обеспечивающих гидродинамическую связь продуктивных и водонасыщенных интервалов.

\section{Ключевые слова:}

Карбонатные трещиноватые коллекторы, трещиноватость, низкопроницаемые коллекторы, концептуальная модель, смачиваемость, обводненность, капиллярное давление, пластовый электрический микросканер, известняки, бокситы, тектоника.

\section{Введение}

Почти половина остаточных запасов Компании «Газпром нефть» приходится на карбонатный тип коллектора, при этом текущая доля добычи из карбонатов в общей структуре добычи Компании невелика, значительная часть карбонатного портфеля находится на стадии геологоразведочных работ и в перспективе планируется увеличение добычи из коллекторов этого типа.

Одним из ярких примеров является Арчинское нефтегазоконденсатное месторождение, расположенное в Томской области Российской Федерации. Разрез рассматриваемой залежи состоит из пачки девонского возраста и представлен низко проницаемыми трещиноватыми коллекторами. Залежь массивная, частично текто- нически экранированная, с газовой шапкой, подстилается по всей площади подошвенной водой [1]. В соответствии с превалирующим типом проницаемости и пористости Арчинское месторождение может быть отнесено ко второму типу по классификации, предложенной Р. Нельсоном [2]. Результаты специальных исследований свидетельствуют о сложном геологическом строении комплекса, что затрудняет детальный прогноз распространения фильтрационно-емкостных свойств коллектора. Кроме того, разрешающая частота сейсмики ограничивает применение полного спектра современных технологий для прогноза продуктивности, латерального распространения трещиноватости и петрофизических характеристик коллектора. 
Месторождение введено в разработку в 1999 г. на естественном режиме. В процессе разработки наблюдаются основные признаки, свойственные объектам со значительным влиянием естественной трещиноватости [2]. Так, в процессе строительства каждой горизонтальной скважины встречаются интервалы высоких поглощений бурового раствора, что зачастую не позволяет достигать запланированных длин горизонтальной секции скважин. Низкий процент выноса керна, высокая латеральная неоднородность фильтрационно-емкостных свойств коллектора, выраженная в значительных различиях коэффициента продуктивности для соседних скважин, также подтверждают наличие вторичной пористости. Более 40 \% скважин, пробуренных с 2016 г., характеризуются темпом обводнения продукции выше запланированного.

\section{Постановка задачи и описание объекта исследования}

Необходимость пересмотра концептуальной модели месторождения обусловлена тем, что текущее представление о геологическом строении и механизмах работы залежи не в полной мере описывает фактическое поведение пласта, что затрудняет подбор технологических решений для оптимизации разработки месторождения, а также не позволяет дать оценку потенциальной эффективности принятых решений.

В рамках предварительного анализа данных по месторождению был выдвинут ряд гипотез, суть которых состоит в предположении зависимости продуктивности скважин от распределения свойств естественной трещиноватости (трещинная ориентация, пористость, проницаемость и интенсивность массообмена с матрицей) и её связи с фациальной неоднородностью коллектора, а также положением и свойствами разломов. Трещины, как естественные, так и механические, являются основными каналами или наоборот барьерами для течения флюида во многих средах. Наличие трещин, которые влияют на течение флюида, характерно для различных типов пористых сред; протяженность трещин изменяется от миллиметров до сотен километров [3].

В работе представлена эволюция концептуальной модели коллектора продуктивного пласта, основанная на комплексном анализе существующих данных, ее численная реализация и направление для оптимизации программы исследовательских работ для месторождений такого типа.

Объектом настоящих исследований являются залежи углеводородов (УВ) в породах комплекса, относящихся к типу массивных, водоплавающих, залегающих в карбонатных отложениях девона, в зоне древнего гипергенеза. Коллекторами являются трещинно-кавернозные известняки, рыхлые продукты гидрохимического выщелачивания глинистых известняков сидерит-кремнистоглинистого состава, вероятно, представляющих стадию перехода известняков в бокситы, трещинные зоны.

По данным описания и фотографий керна известняки в приповерхностной зоне довольно сильно изменены. Изменения главным образом гипергенного характера с развитием повышенной трещиноватости за счет расширения их объема в результате гидрохимического воздействия вод, обогащенных кислородом в приповерхностной зоне. Это способствовало формированию карста, кавернозности [4]. Большое значение здесь имеют процессы растворения карбонатных пород. На качество коллекторов в зоне гипергенного изменения пород значительное влияние оказывают процессы бокситообразования. По условиям образования бокситы в пределах площади классифицируются как карстовые, латеритные и элювиальные [5]. Анализ результатов интерпретации геофизических исследований скважин (РИГИС), описания и фотографий керна указывает на то, что каменистые разности бокситов являются непроницаемыми для флюидов, рыхлые - проницаемы.

Однако до представленной работы комплексный анализ геологии и данных добычи не был проведён и не было установлено влияние бокситов на разработку. В данной статье были рассмотрены несколько концепций и предложен наиболее оптимальный вариант, описывающий текущую геологическую модель, подтверждаемую данными добычи.

\section{Концепция решения}

В процессе разработки месторождения недропользователем успешно выполняется программа исследовательских работ. Однако имеющихся на месторождении исследований оказалось недостаточно для снятия неопределенностей, поэтому была составлена матрица гипотез о возможных факторах, влияющих на динамику работы скважин (таблица).

В идеале происходит сбор и диагностика параметров матрицы и трещин на основе скважинной информации. Для каждой скважины рассматриваемого типа (горизонтальная, вертикальная, добывающая, нагнетательная и т. д.) все доступные показатели из перечисленных ниже собираются, анализируются и нормализуются для целей сравнения:

- отношение проницаемостей по испытаниям скважин с проницаемостями по керну;

- отчет о поглощениях бурового раствора;

- пики добычи по промыслово-геофизическим исследованиям (ПГИ);

- оценка параметров пласта по гидродинамическим исследованиям скважин (ГДИС);

- индексы продуктивности, нормализованные на длину закачивания скважины (при отсутствии интерпретированных данных испытаний скважины);

- время, прошедшее до прорыва воды;

- накопленная добыча нефти и т. д. [6]

В условиях недостаточности данных было решено проверить ряд гипотез на основе многовариантного моделирования [7]. При решении этой задачи основное назначение гидродинамической модели не прогнозный расчет, а комплексирование и оценка соответствия единой концепции различной геологической информации: структурной, литолого-фациальной, петрофизической моделей, результатов ГДИС и ПГИ, динамики работы скважин. 
Таблииа. Схематичное представление матрииы гипотез Table. $\quad$ Schematic representation of the hypothesis matrix

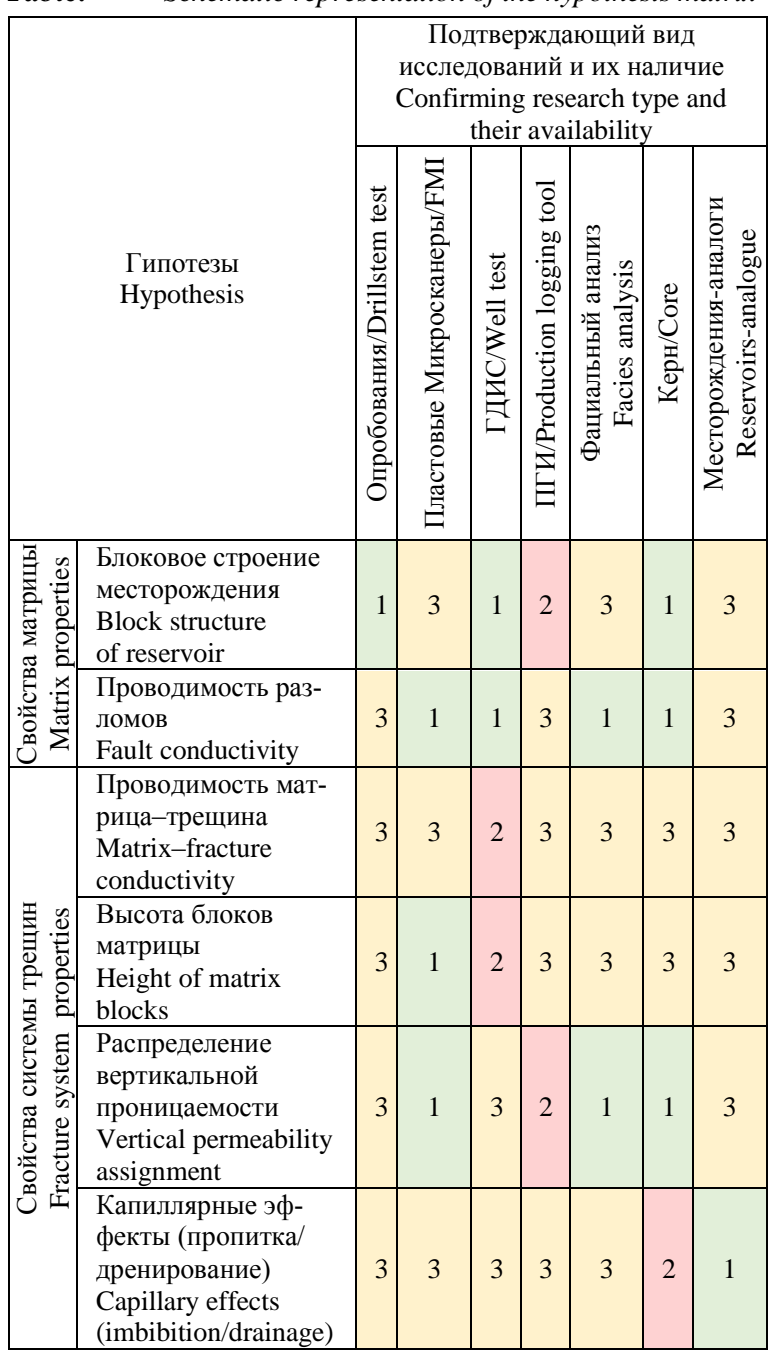

1 - подтверждено/confirmed; 2 - нет данных/no data 3 -ограничено/limited

Один из результатов проведенного анализа необходимость детализации существующей модели и пересмотра результатов интерпретации части исследований, не вписывающихся в общую концепцию и противоречащих фактической истории разработки месторождения.

\section{Анализ исходных данных и моделирование}

Для определения зависимости динамики работы от геологических и технологических условий произведена кластеризация скважин. Скважины с разным типом заканчивания рассматривались отдельно.

Горизонтальные скважины по характеру обводненности продукции разделены на две основные группы:

1) скважины со стартовой обводненностью менее $20 \%$ и плавным ростом обводнения продукции в дальнейшем;

2) скважины с начальной обводненностью более $20 \%$ и дальнейшим ростом обводненности.

Зависимостей стартовой обводненности скважин от нефтенасыщенных толщин, изменения структур- ных отметок или суммарной длины интервалов поглощения не выявлено. Как и предполагалось, для горизонтальных скважин получена прямая зависимость величины начальной обводненности от расстояния до уровня водонефтяного контакта (ВНК) с коэффициентом корреляции 0,7 (рис. $1, a$ ).

Среди вертикальных скважин выделены три группы по характеру динамики обводненности:

1) со стартовой обводненностью менее $10 \%$;

2) с начальной обводненностью более $60 \%$;

3) с постоянным уровнем обводненности в течение всего времени работы.

Закономерности в расположении групп по площади месторождения не выявлено. Также не обнаружено зависимости между начальной обводненностью и расстоянием от нижних дыр перфорации до уровня ВНК (рис. 1, б).

В итоге был сделан вывод о том, что обводнение скважин преимущественно происходит по трещинам, обеспечивающим гидродинамическую связь между продуктивными интервалами и подстилающей водой. Горизонтальные скважины пересекают значительно большее число трещин, чем вертикальные, что и объясняет хорошую зависимость динамики обводнения от расстояния до ВНК именно для скважин с горизонтальным типом заканчивания.

Комплексный анализ исходных данных (интерпретация пластовых микроимиджеров FMI, модульного динамического испытателя пластов MDT, VISO, ГДИС, керн) (рис. 2) позволяет сделать предположения о распределении вертикальной проницаемости, свойствах разломов и строении коллектора. Исследования показали наличие большого количества равномерно распределенных по стволу скважины трещин, однако апертуры трещин по разрезу значительно разнятся. Чаще всего апертура определяется по данным микроимиджеров. Теоретическая минимальная апертура, которая может быть обнаружена инструментом (в различных условиях), оценивается на основе комбинации: контраста удельного сопротивления трещины и фона; превышения размера пика проводимости обнаруженного выше уровня шума и изменения размера пика из-за отклонения зонда от стенки скважины. Наиболее значимое влияние на минимальную определимую апертуру имеет проводимость жидкости, заполняющей трещину $[8,9]$.

Стоит отметить, что по результатам исследований также выделяются интервалы с отсутствием трещин. При сопоставлении VISO и FMI установлено, что верхняя часть разреза характеризуется более высокими значениями трещинной и кавернозной пористости.

Указанные выше факторы позволяют сделать следующие предположения о характере вертикальной проницаемости:

1) чередование проницаемых и непроницаемых слоев;

2) рассматриваемый пласт можно представить двумя характерными интервалами, при этом проницаемость прикровельной части значительно выше;

3) наблюдается вертикальная анизотропия, обусловленная неоднородным строением системы трещин (различные плотности и апертуры трещин). 


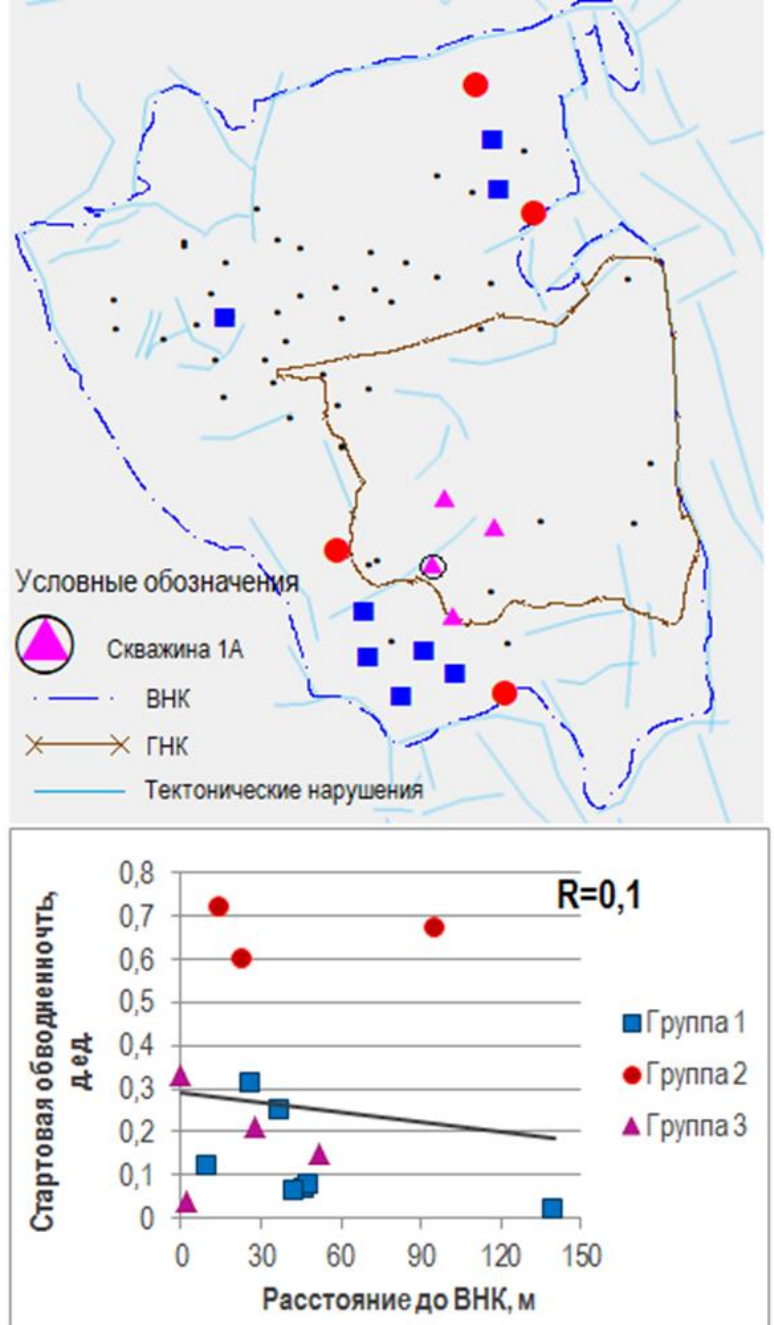

$a / a$
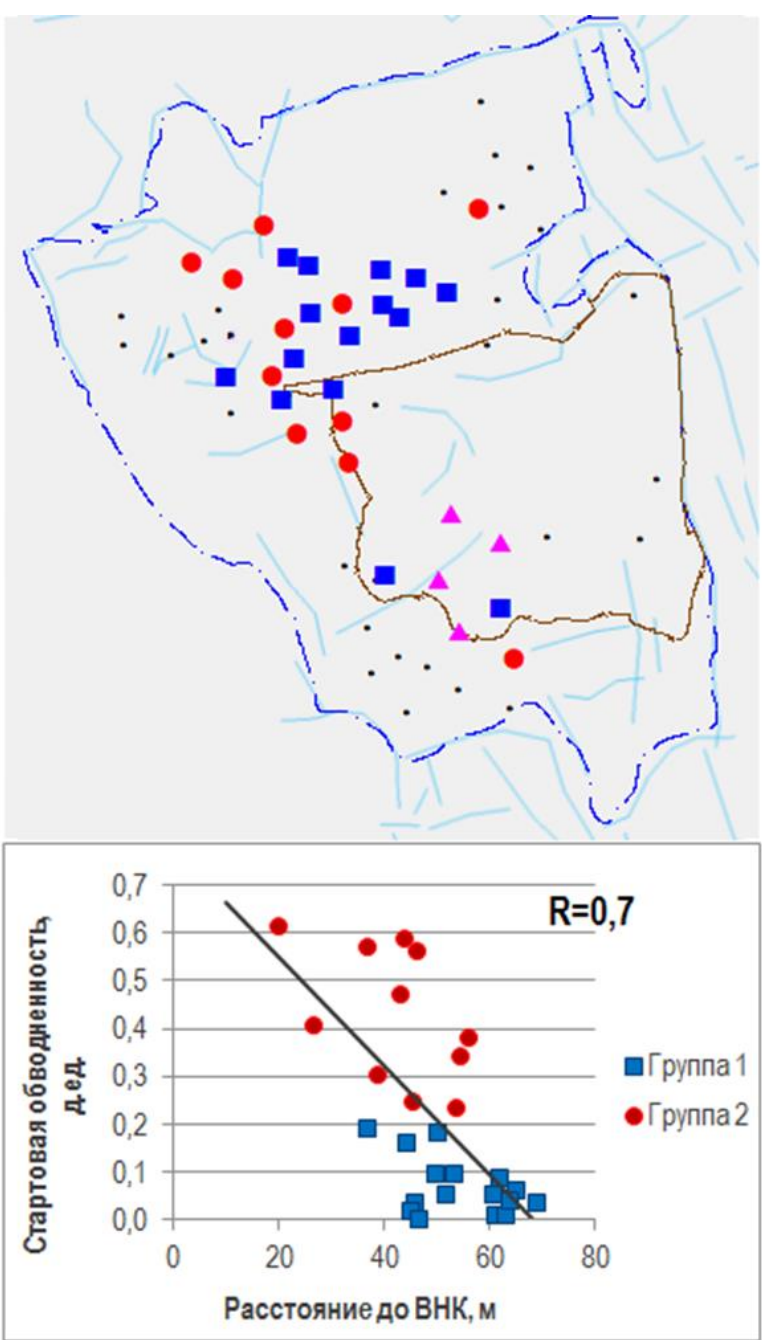

$\sigma / b$

Pис. 1. Кластеризация скважин: а) вертикальные скважины, б) горизонтальные скважсины Fig. 1. Well clustering: a) vertical wells, b) horizontal wells
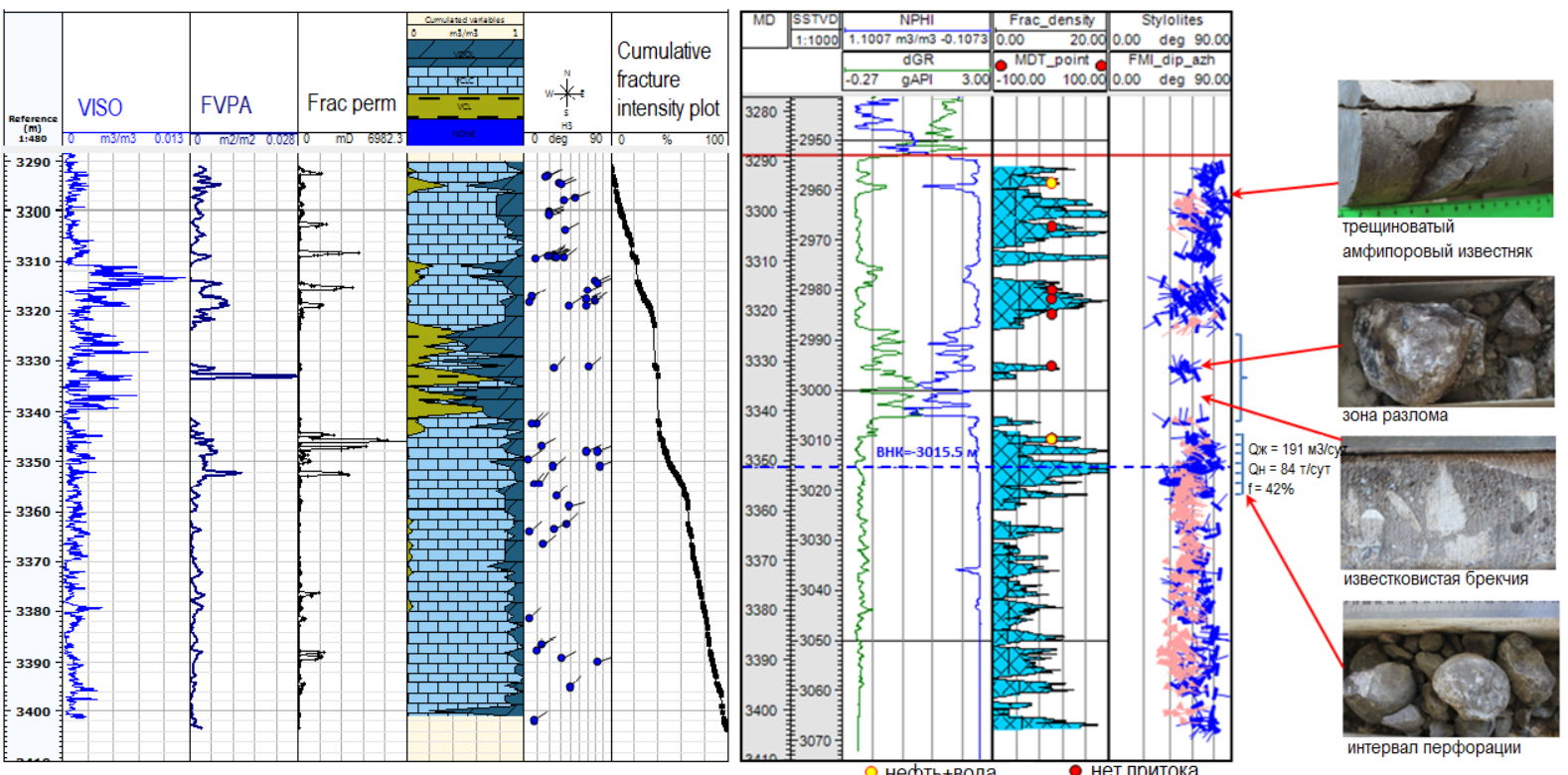

Pис. 2. Комплексный анализ данных на примере скважины $1 \mathrm{~A}$

Fig. 2. Comprehensive data analysis on the example of well $1 \mathrm{~A}$ 
Скважина 1А пересекает субширотный разлом (рис. 1), в котором по данным FMI зафиксировано только две частично проводящие трещины. По описанию керна разломная зона представлена известняковыми брекчиями с матриксом заполнения карстовых полостей (бокситоносный латерит), что соответствует породам коры выветривания. Остальная часть разреза представлена органогеннообломочным трещиноватым известняком. Принимая во внимание результаты интерпретации ГДИС, которые показывают наличие непроницаемых границ по площади Арчинского месторождения, и данные эксплуатации скважин, можно предположить, что в районе субширотных разломов наблюдается ухудшение коллекторских свойств пласта, а сами разломы являются частично проводящими [10]. Гипотезы о характере вертикальной проницаемости были проверены с помощью гидродинамического моделирования и наилучшее совпадение с фактом получено для гипотезы 3, согласно которой пласт, контролирующий массивную залежь углеводородов, имеет разную степенью трещиноватости.

Помимо свойств самой системы трещин, важным параметром, влияющим на разработку трещиноватых коллекторов, является характеристика взаимодействия между матрицей и трещинами. В зависимости от размеров матрицы и проницаемостей системы матрица-трещины, трещинные коллекторы могут разрабатываться несколькими технологиями добычи: разработка без воздействия на пласт, газонапорный режим (режим газовой шапки или растворенного газа с возможным явлением конвекции), заводнение, смешивающееся или несмешивающееся вытеснение при закачке газа и методы увеличения нефтеотдачи [11]. Различные технологии эксплуатации залежи, такие как пропитка, вытеснение водой, гравитационный дренаж, перепропитка или диффузия, также могут влиять на динамику добычу. Важным фактором здесь является смачиваемость коллектора [12]. Рассматриваемые породы Арчинского месторождения в основном являются гидрофобными, либо со смешанной смачиваемостью.

Особенностью для пород смешанного типа является сочетание механизмов «дренирования» и «пропитки» [13]. При высокой водонасыщенности системы трещин, окружающей матрицу, вода не будет проникать в матрицу и будет циркулировать по системе трещин. В диапазоне «принудительной пропитки» проникновение воды в матрицу будет определяться депрессиями, существующими в пласте при разработке. При «самопроизвольной пропитке» обеспечивается выработка гидрофильной части породы. Взаимодействие трещин и матрицы происходит в нефтяной, газовой и водной зоне, которые для трещин имеют резко выраженные границы. В зависимости от характера смачиваемости матрицы определяется степень вытеснения нефти водой («пропитка»). Возможность гравитационного дренирования в системе трещин зависит от высоты блоков матрицы и характерного капиллярного давления в матрице. Блоки матрицы хорошо работают в двух случаях:
- при высоком значении проницаемости и низких капиллярных давлениях;

- при больших геометрических размерах блока (критический размер блоков определяется соотношением капиллярного давления и давления на противоположных гранях блока матрицы).

Если внешний перепад давления не превышает капиллярное давление, то возникает препятствие процессу дренирования и нефть удерживается внутри матрицы [14]. Таким образом, существенную роль при дренировании начинают играть размеры блоков матрицы. В коллекторах с малыми размерами блоков возможны случаи, когда газ или вода обходят нефтенасыщенный блок, при этом нефть не извлекается и полностью остается в матричном блоке. Комбинированные кривые капиллярного давления имеют ветвь, находящуюся в области отрицательных значений капиллярного давления. С физической точки зрения это объясняется тем, что в гидрофильной горной породе всегда существует связанная часть гидрофобизированных пор и для проникновения в нее воды необходимо приложить определенное давление [15].

В связи с отсутствием исследований капиллярного давления для разных режимов на керне композиционные кривые капиллярного давления строились с использованием данных по месторожденияманалогам. Критериями применимости месторождения в качестве аналога были приняты степень смачиваемости, а также капиллярное число

$$
\sqrt{(k / m)},
$$

где $k$ - проницаемость; $m$ - пористость образца.

Проанализировав форму и точки перегиба капиллярных кривых при остаточной водо- и нефтенасыщенности, из исходной кривой «дренирования» Арчинского месторождения масштабированием построена кривая для «пропитки» и получена комбинированная кривая капиллярного давления. Результаты гидродинамического моделирования показали существенное различие расчетных параметров при использовании композиционной кривой капиллярного давления и учета режимов пропитки и дренирования. Значительно улучшилось совпадение расчетных и фактических данных разработки [16].

Композиционная кривая капиллярного давления позволяет вычислить критическую высоту блока матрицы, необходимую для гравитационного дренирования нефти водой в гидрофобном коллекторе [8]. Из-за отсутствия собственных композиционных кривых капиллярного давления невозможно провести такие вычисления, однако результаты интерпретации микроимиджеров и построение модели трещин позволяют решить так называемую «обратную задачу» и, исходя из размеров блоков матрицы, определить давление, необходимое для полного замещения в них нефти водой. Считается, что для правильного учета большого перепада давления размер ячейки должен быть достаточно маленьким [17]. Среднее значение высоты блоков матрицы по результатам FMI - 0,6 м, минимальное - 0,01 м, максимальное - 5 м. По результатам расчетов получены намного меньшие значения капиллярного 
давления, чем по месторождениям-аналогам. Эти результаты показывают высокий приоритет необходимости отбора собственного керна и выполнения дополнительных экспериментов для построения корректной композиционной капиллярной кривой.

На следующем этапе актуализации концептуального представления о строении залежи были пересмотрены значения уровней ВНК и газонефтяного контакта (ГНК), а также проанализированы результаты всех специальных исследований с учетом новой промысловой информации, что привело к обновлению и детализации модели системы трещин. Количество скважин с полным комплексом данных невелико и в основном ими охвачена только южная часть площади месторождения.

По описанию керна выделяются следующие литологические разности:

- известняк серый, буровато-серый, крепкий, с многочисленными разнонаправленными трещинами, залеченными кальцитом и сидеритом, с включениями линз и прослоев аргиллитов, углистого материала;

- кремнисто-глинистые породы; зоны карстовых известняковых брекчий и бокситоносного латерита, которые относятся к породе коры выветривания.

Процент выноса керна изменяется в диапазонах от 10-50 до 90-100 \%; керн разрушен в интервалах обеих литологических разностей. Вторичные процессы в виде кавернозности и доломитизации наблюдаются не во всех скважинах - порода пласта была слабо подвержена вторичным-катагенетическим преобразованиям [18].

Таким образом, все скважины можно условно разделить на две группы:

1) скважины, где в объёме продуктивного пласта прослои коры выветривания полностью отсутствует либо их количество невелико;

2) скважины, в которых наблюдается частое переслаивание известняков и отложений коры выветривания.

Для скважин из каждой группы проведено сопоставление описания керна и результатов интерпретации микроимиджеров. Качество имиджеров оценено как среднее: в интервалах, обозначенных как трещиноватые известняки на керне, изображение является четким; в брекчиевидных интервалах бокситоносных латеритов изображение часто размыто из-за наличия затяжек прибора и обвалов стенок скважины. Выделение трасс трещин в брекчиях затруднено, поэтому на графике интенсивности, накопленной по стволу скважины трещин, данные интервалы нарушают тренд, но в остальных частях вид трасс говорит о равномерном развитии трещин по разрезу. Среднее значение плотности трещин составляет порядка 5-10 трещин/м. Ориентация проводящих трещин хаотична, но преобладает система направления 340-350 градусов СЗ-ЮВ. Для ряда скважин проинтерпретированы трещины, залеченные кальцитом; преобладающее направление - 3-В. Апертура трещин колеблется в диапазоне 100-500 мкм - данный диапазон соответствует значениям макротрещин, характеризующихся большой протяженностью и системностью. Для прогноза в скважинах интервалов известняка и бокситоносных латеритов использовались результаты интерпретации стандартного комплекса геофизических исследований скважин (ГИС), поскольку конечным продуктом модели фаций является трехмерный объем, представляющий распределение фаций в пласте [19].

Анализ ГИС показал, что литологические типы можно разделить по данным интервального времени пробега продольной волны и динамического модуля Юнга. Эта информация была использована для сопоставления с результатами опробований скважин. Отсутствие ПГИ не позволяет точно определить интервалы притока, но по скважинам с MDT видно, что в интервалах коры выветривания приток отсутствует (рис. 3).

Таким образом, получено следующее концептуальное представление о строении пласта, согласующееся с данными разработки: в процессе денудации и выветривания палеозойского комплекса по зонам разуплотнения породы и проводящей трещиноватости произошло проникновение глинистого материала, породы коры выветривания, формирование карстовых пустот и брекчий, впоследствии образовавших барьеры для потока и ухудшающих вертикальную проницаемость. Концепция была использована при актуализации численной гидродинамической модели (рис. 5). Необходимо отметить, что для расчетов использовалась модель двойной пористости (рис. 4). Модель двойной пористости предполагает, что основные запасы углеводородов сосредоточены в матрице, а приток жидкости к скважинам осуществляется по системе трещин [20], что согласуется с обновленной концептуальной моделью коллектора. Псевдопараметры, особенно псевдоотносительные проницаемости, должны быть присвоены ячейкам матрицы и трещин [21]. Для увеличения прогнозной способности модели необходим поиск технических решений для детального прогноза интервалов ухудшенных фильтрационно-емкостных свойств (ФЕС) в межскважинном пространстве. Что в конечном счете необходимо для расчета коэффициента извлечения нефти (КИН). Максимальный КИН является целью любого проекта разработки месторождения [22].

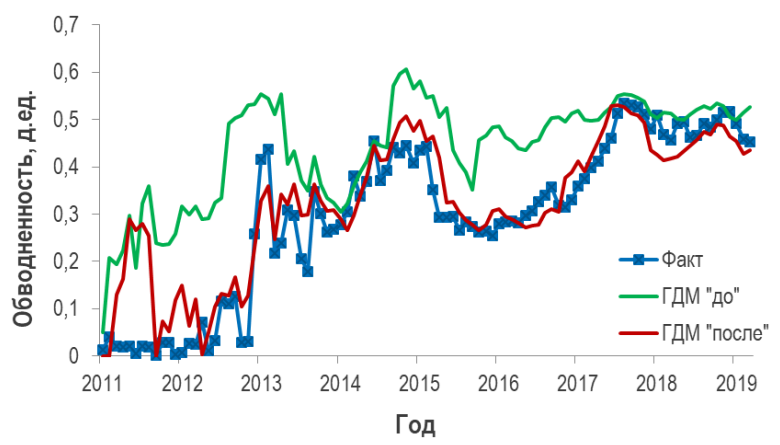

Рис. 5. Сопоставление адаптациии гидродинамической модели до и после уточнения концептуального строения коллектора

Fig. 5. Comparison of model history matching before and after clarification of the conceptual structure of the reservoir 
Известия Томского политехнического университета. Инжиниринг георесурсов. 2020. Т. 331. № 9. 39-48 Ахмерова А.В. и др. Эволюция концептуальной модели низкопроницаемого трещиноватого коллектора

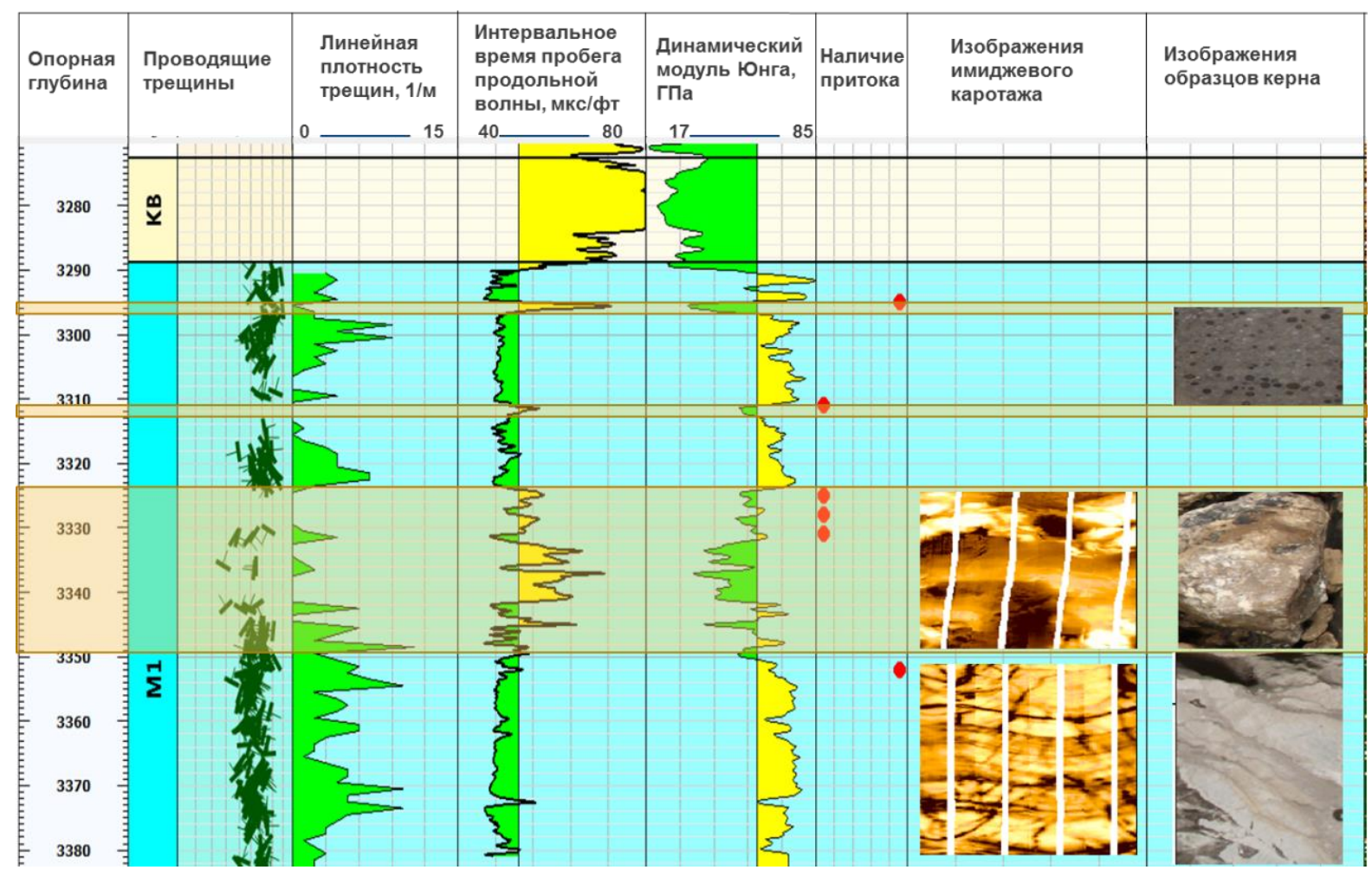

Рис. 3. Сопоставление интервалов притока по модульному динамическому испьтателю пластов и литологического состава породы

Fig. 3. Comparison of modular dynamic tester flow intervals and rock lithology
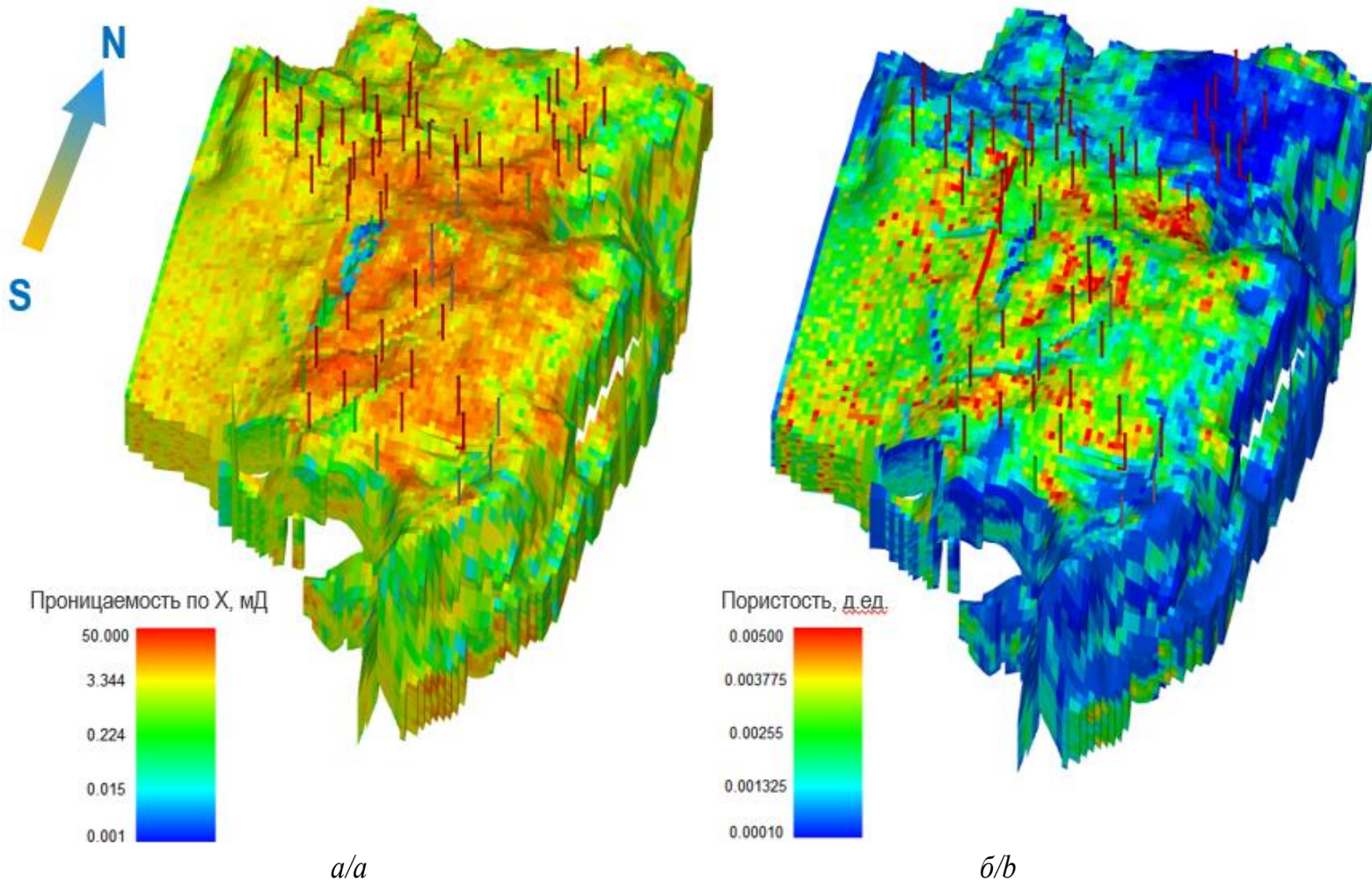

Рис. 4. Параметры системы трещин после адаптаџии гидродинамической модели: а) проницаемость в направлении $X$; б) пористость

Fig. 4. Parameters of the fracture system after history matching of the reservoir model: a) permeability in the $X$ direction; b) porosity 


\section{Заключение}

Интегрированный подход к анализу результатов проведенных исследований, аналитических и численных расчетов, а также информации о работе скважин позволил актуализировать представление о геологическом строении и основных механизмах работы рассматриваемой залежи. Обновленная концептуальная модель предполагает, что коллектор продуктивного пласта Арчинского месторождения представлен породами двух типов: известняками и бокситоподобными породами. Известняки отличаются значительной трещиноватостью, в то время как бокситоподобные породы являются непроницаемыми и выступают барьерами для потока. Трещиноватость, обусловленная тектоническим фактором, характеризуется равномерным распределением по разрезу и площади месторождения и

\section{СПИСОК ЛИТЕРАТУРЬ}

1. Абросимова О.О., Белова Е.В. Резервуары углеводородов в эрозионно-тектонических выступах доюрских пород юговосточной части Западно-Сибирской плиты [Томская область] // Геология нефти и газа. -2000 . - № 3. - С. 17-21.

2. Nelson R.A. Geological analysis of naturally fractured reservoirs. - Houston, TX: Gulf Professional Publishing, 2001. - 332 p.

3. Berre I., Doster F., Keilegavlen E. Flow in fractured porous media: a review of conceptual models and discretization approaches // Transport in Porous Media. - 2018. - № 130. - P. 215-236. URL: https://link.springer.com/article/10.1007/s11242-018-1171-6 (дата обращения 08.12.2019).

4. Уилсон Дж.Л. Карбонатные фации в геологической истории / Пер. с англ. - М.: Недра, 1980. - 463 с.

5. Смирнов В.И. Геология полезных ископаемых. - М.: Недра, 1976. $-688 \mathrm{c}$.

6. Bourbiaux B. Fractured reservoir simulation: a challenging and rewarding issue // Oil \& Gas Science and Technology - Review French Institute of Petroleum - 2010 - V. 65 - № 2 - P. 227-238.

7. Косентино Л. Системные подходы к изучению пластов. - М. Ижевск: Институт компьютерных исследований, НИЦ «Регулярная и хаотическая динамика», 2007. - 400 c.

8. Dubourg D., Quesada W.A. ElNour // International Petroleum Technology Conference Paper. - Qatar, 2015. URL: https://www.onepetro.org/conference-paper/IPTC-18355-MS (дата обращения 08.12.2019).

9. Reiss L.H. The reservoir engineering aspects of fractured formations. - Paris: Editions Technip, 1980. - 108 p.

10. Славкин В.С., Шик Н.С., Сапрыкина А.Ю. К вопросу дизъюнктивно-блокового строения природных резервуаров Западно-Сибирского НГБ // Геология нефти и газа. - 2001. - № 4. C. $40-46$.

11. Lemonnier P., Bourbiaux B. Simulation of naturally fractured reservoirs. State of the art // Oil \& Gas Science and Technology - Review French Institute of Petroleum. - 2010. - V. 65. - № 2. - P. 239-262.

12. Leverett M.C. Capillary behavior in porous solids // Transactions of the American Institute of Mining, Metallurgical, and Petroleum Engineers Journal. - 1941. - V. 142. - P. 152-169.

13. Голф-Рахт Т.Д. Основы нефтепромысловой геологии и разработки трещиноватых коллекторов. - М.: Недра, 1986. - 608 с. является параметром, наиболее влияющим на технологические показатели разработки. Технологический режим эксплуатации некоторых скважин и высокие депрессии приводят к конусообразованию по системе трещин, обеспечивающей гидродинамическую связь продуктивных и водонасыщенных интервалов. Расчетные значения высоты блоков матрицы варьируются в интервале от 0,01 до 5 м, что исключает возможность гравитационного дренирования нефти водой. Определены приоритетные направления развития программы исследовательских работ для месторождения. Основные усилия будут направлены на уточнение геометрических характеристик вторичной пустотности, определение взаимодействия между матрицей и системой трещин, уточнение текущих уровней водонефтяного и газонефтяного контактов.

14. Ryazanov A.V., Sorbie K.S., van Dijke M.I.J. Structure of residual oil as a function of wettability using pore-network modelling // Advances in Water Resources. - 2014. - № 63. - P. 11-21.

15. Свалов А.М. Анализ проблем построения кривых капиллярного давления при моделировании пластовых процессов // Нефтяное хозяйство - 2015. - № 5. - С. 70-73.

16. Numerical simulation of water-oil flow in naturally fractured reservoirs / H. Kazemi, L.S. Merrill, K.L. Porterfield, P.R. Zeman // SPE Journal. - 1976. - V. 16. - P. 317-326.

17. Ding X.Y. Using unstructured grids for modeling complex discrete fracture network in unconventional reservoir simulation // SPE Conference Paper. - Bahrain, 2019. URL: https://www. onepetro.org/conference-paper/SPE-195051-MS (дата обращения 08.12.2019).

18. Ковешников А.Е., Недоливко Н.М. Вторичнокатагенетические преобразования доюрских пород ЗападноСибирской геосинеклизы // Известия Томского политехнического университета. - 2012. - Т. 320. - № 1. - С. 82-86.

19. Gomes J., Parra H., Ghosh D. Quality control of 3D GeoCellular models: examples from UAE carbonate reservoirs // SPE Conference Paper. - Abu Dhabi, 2018. URL: https://www.onepetro.org/conference-paper/SPE-193128-MS (дата обращения 08.12.2019).

20. Korigiv R., Kharitontseva P. Creation of an applicability matrix of modeling methods depending on the complexity of pore space for carbonate fractured reservoirs // EAGE Conference Paper. - Saint Petersburg, 2018. - V. 2018. - P. 1-5. URL: https://www.earthdoc.org/content/papers/10.3997/22144609.201800229 (дата обращения 08.12.2019).

21. An integrated workflow to account for multi-scale fractures in reservoir simulation models: implementation and benefits / $\mathrm{B}$. Bourbiaux, R. Basquet, M. Cacas, J. Daniel // SPE Conference Paper. - Abu Dhabi, 2002. URL: https://www.onepetro.org/ conference-paper/SPE-78489-MS (дата обращения 08.12.2019).

22. Benchmarking recovery factors for carbonate reservoirs: key challenges and main findings from middle eastern fields / J. Gomes, R. Narayanan, H. Parra, L. Saputelli, Y. Bansal // SPE Conference Paper. - Abu Dhabi, 2018. URL: https://www.onepetro.org/ conference-paper/SPE-193094-MS (дата обращения 08.12.2019).

Поступила: 13.12 .2019 2.

\section{Информация об авторах}

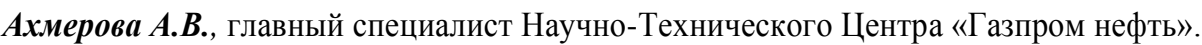

Галлямова Д.Ч., главный специалист Научно-Технического Центра «Газпром нефть».

Мельников A.B., руководитель программ по разработке карбонатных коллекторов Научно-Технического Центра «Газпром нефть».

Харитонцева П.А., эксперт Лаборатории разработки месторождений нефти и газа Инженерной школы природных ресурсов Национального исследовательского Томского политехнического университета. 
UDC 550.8.053; 550.8.056

\title{
EVOLVING OF A LOW PERMEABILITY FRACTURED RESERVOIR CONCEPTUAL MODEL
}

\author{
Alina V. Akhmerova ${ }^{1}$, \\ Akhmerova.AV@gazpromneft-ntc.ru \\ Dilia Ch. Gallyamova ${ }^{1}$, \\ Gallyamova.DCh@gazpromneft-ntc.ru \\ Alexandr V. Melnikov' \\ Melnikov.AVik@gazpromneft-ntc.ru \\ Polina A. Kharitontseva², \\ Kharitontsevapa@hw.tpu.ru \\ 1 Gazprom Neft Scientific and Technical Center, \\ 75-79 liter D, Moika River embankment, St. Petersburg, 190000, Russia. \\ 2 National Research Tomsk Polytechnic University, \\ 30, Lenin avenue, Tomsk, 634050, Russia.
}

The relevance of the research is caused by the need to study complex, heterogeneous fractured carbonate reservoirs, which are one of the sources of hydrocarbon production in an age of depleted clastic reservoirs resources.

The main aim of the research is the revision of the conceptual model of the field, since the current model does not fully describe the actual behavior of the formation, complicates the selection of technological solutions for field development and optimizing, and does not allow an assessment of the potential effectiveness of the decisions made.

Object of the research is the M1 reservoir is gas-condensate-oil, massive type, with a gas cap, confined to the ledge of the carbonate basement of the Devonian age at the Archinsky deposit.

Methods: an integrated approach to the analysis of research results, analytical and numerical calculations, systematization, generalization, structuring of initial information on the field, simulation of several concepts, comparison with actual data.

Results. The authors presented an alternative scenario of the geological structure and the main production mechanisms of the reservoir. Since the current model did not describe the actual behavior of the reservoir, the results of special studies indicate a complex geological structure of the complex, which made it difficult to predict the distribution of reservoir properties. Moreover, the resolving frequency of seismic data limits the use of a full range of modern technologies for predicting productivity, lateral propagation of fractures, and petrophysical characteristics of a reservoir. The updated conceptual model assumes that according to the core description and geophysical studies of the Archinsky field, rocks of two types represent it: limestone and bauxite-like rocks. Fracturing of limestones, caused by the tectonic factor, is characterized by a uniform distribution over the section and the area of the field, and is the most influential parameter on the technological indicators of development. The technological mode of some wells and high depressions lead to water conning through a system of fractures that provide a hydrodynamic relation between productive and water-saturated intervals.

\section{Key words:}

Fractured carbonate reservoirs, fracturing, low permeable reservoirs, concept model, wettability, water cut, capillary pressure, formation microimager, limestones, bauxites, tectonic.

\section{REFERENCES}

1. Abrosimova O.O., Belova E.V. Hydrocarbon reservoirs in erosivetectonic ledge of pre-Jurassic rocks in south-east part of Western Siberian Plate (Tomsk region). Geology of oil and gas, 2000, no. 3 , pp. 17-21. In Rus.

2. Nelson R.A. Geological analysis of naturally fractured reservoirs. Houston, TX, Gulf Professional Publishing, 2001. 332 p.

3. Berre I., Doster F., Keilegavlen E. Flow in fractured porous media: a review of conceptual models and discretization approaches. Transport in Porous Media, 2018, no. 130, pp. 215-236. Available at: https://link.springer.com/article/10.1007/s11242-018-1171-6 (accessed 08 December 2019).

4. Wilson J.L. Karbonatnye fatsii v geologicheskoy istorii [Carbonate facies in geologic history]. Translate from English. Moscow, Nedra Publ., 1980. 463 p.

5. Smirnov V.I. Geologiya poleznykh iskopaemykh [Mineral geology] Moscow, Nedra Publ., 1976. 688 p.

6. Bourbiaux B. Fractured reservoir simulation: a challenging and rewarding issue. Oil \& Gas Science and Technology - Review French Institute of Petroleum, 2010, vol. 65, no. 2, pp. 227-238.

7. Cosentino L. Sistemnye podkhody k izucheniyu plasta [Integrated reservoir studies]. Moscow, Institute of computer researches, 2007. $400 \mathrm{p}$.
8. Maeso C., Dubourg I., Quesada D., ElNour W.A. Uncertainties in fracture apertures calculated from electrical borehole images. International Petroleum Technology Conference Paper. Qatar, 2015. Available at: https://www.onepetro.org/conference-paper/IPTC18355-MS (accessed 08 December 2019).

9. Reiss L.H. The reservoir engineering aspects of fractured formations. Paris, Editions Technip, 1980. 108 p.

10. Slavkin V.S., Shik N.S., Saprikin A.U. To the question of the disjunctive-block structure of natural reservoirs of the West Siberian NGB. Geology of oil and gas, 2001, no. 4, pp. 40-46. In Rus.

11. Lemonnier P., Bourbiaux B. Simulation of naturally fractured reservoirs. State of the art. Oil \& Gas Science and Technology Review French Institute of Petroleum, 2010, vol. 65, no. 2, pp. 239-262.

12. Leverett M.C. Capillary behavior in porous solids. Transactions of the American Institute of Mining, Metallurgical, and Petroleum Engineers Journal, 1941, vol. 142, pp. 152-169.

13. Van Golf-Racht T.D. Osnovy neftepromislovoy geologii i razrabotki treshchinovativkh kolleltorov [Fundamentals of fractured reservoir engineering]. Moscow, Nedra Publ., 1986. 608 p.

14. Ryazanov A.V., Sorbie K.S., van Dijke M.I.J. Structure of residual oil as a function of wettability using pore-network modelling. Advances in Water Resources, 2014, no. 63, pp. 11-21. 
15. Svalov A.M. Analysing problems of capillary curves definition at modelling of formation processes. Oil industry, 2015, no. 5, pp. 70-73. In Rus.

16. Kazemi H., Merrill L.S., Porterfield K.L., Zeman P.R., Numerical simulation of water-oil flow in naturally fractured reservoirs. SPE Journal, 1976, vol. 16, pp. 317-326.

17. Ding X.Y. Using unstructured grids for modeling complex discrete fracture network in unconventional reservoir simulation. SPE Conference Paper. Bahrain, 2019. Available at https://www.onepetro.org/conference-paper/SPE-195051-MS (accessed 08 December 2019).

18. Koveshnikov A.E., Nedolivko N.M. Secondary catagenetic transformations of prejurassic adjournment of the Western-Siberian geosineclise. Bulletin of the Tomsk Polytechnic University, 2012, vol. 320, no. 1, pp. 82-86. In Rus.

19. Gomes J., Parra H., Ghosh D. Quality control of 3D GeoCellular models: examples from UAE carbonate reservoirs. SPE Conference Paper. Abu Dhabi, 2018. Available at: https://www.onepetro.org/conference-paper/SPE-193128-MS (accessed 08 December 2019).

\section{Information about the authors}

Alina V. Akhmerova, chief specialist, Gazprom Neft Scientific and Technical Center.

Dilia Ch. Gallyamova, chief specialist, Gazprom Neft Scientific and Technical Center.

Alexandr V. Melnikov, manager, Gazprom Neft Scientific and Technical Center.

Polina A. Kharitontseva, expert, National Research Tomsk Polytechnic University.
20. Korigiv R., Kharitontseva P. Creation of an applicability matrix of modeling methods depending on the complexity of pore space for carbonate fractured reservoirs. EAGE Conference Paper. Saint Petersburg, 2018. Vol. 2018, pp. 1-5. Available at: https://www.earthdoc.org/content/papers/10.3997/22144609.201800229 (accessed 08 December 2019)

21. Bourbiaux B., Basquet R., Cacas M. Daniel J. An integrated workflow to account for multi-scale fractures in reservoir simulation models: implementation and benefits. SPE Conference Paper. Abu Dhabi, 2002. Available at: https://www.onepetro.org/conferencepaper/SPE-78489-MS (accessed 08 December 2019).

22. Gomes J., Narayanan R., Parra H., Saputelli L., Bansal Y. Benchmarking recovery factors for carbonate reservoirs: key challenges and main findings from middle eastern fields. SPE Conference Paper. Abu Dhabi, 2018. Available at: https://www.onepetro.org/ conference-paper/SPE-193094-MS (accessed 08 December 2019).

Received: 13 December 2019. 